\title{
Meta-analyses of fertility desires of people living with HIV
}

\author{
Yifru Berhan ${ }^{*}$ and Asres Berhan
}

\begin{abstract}
Background: Literature review has shown that some years back the fertility desires of people living with HIV was low but in the recent years, it was reported as increasing. However, little is known about the strength of association of fertility desire of HIV positive people with antiretroviral therapy (ART) experience, age, sex, education level, and number of children.

Methods: In these meta-analyses, twenty studies from different parts of the world were included. The odds ratios of fertility desires were determined using the random-effects model. Heterogeneity among the studies was assessed by computing values for Tau ${ }^{2}, C$ Chi-square $(Q), I^{2}$ and $P$-value. Sensitivity analysis and funnel plot were done to assess the stability of pooled values to outliers and publication bias, respectively.

Results: The pooled analysis demonstrated that fertility desires of study participants had no association with ART. Similarly, the overall odds ratio did not show statistically significant association of fertility desires with sex and educational attainment of study participants although forest plots of some studies fall on increased and some others on decreased sides of fertility desires. The two variables that demonstrated a strong association with fertility desires were age less than 30 years and being childless. The lowest heterogeneity was found in a meta-analysis comparing ART experienced and ART naïve HIV positive people. In all meta-analyses, the sensitivity analyses showed the stability of the pooled odds ratios; and the funnel plots did not show publication or disclosure bias.

Conclusion: Although the fertility desires among childless and younger age group was very strong, we realized that quite a significant segment of HIV-infected people have desire for fertility. Therefore, including fertility issue as integral part of HIV patient care may help several of them in their reproductive decision making (letting them know the risks and methods of prevention while anticipating pregnancy).
\end{abstract}

Keywords: ART, Fertility desire, Meta-analysis, HIV positive, Sensitivity analysis

\section{Background}

Before the era of HIV, wishing to have a biological child and preserving the continuity of their family to the future generation is perhaps a common thought of all and this is also expected to be same in these days in the majority of individuals who are sero-negative for HIV. However, several studies have shown that the fertility desire of people living with HIV was found to be significantly reduced [1-4]. A national survey in Cameroon revealed that women's fertility desire was about $55 \%$ and the main factor independently associated with this desire was having good physical health [5]. In other African

\footnotetext{
* Correspondence: yifrub@yahoo.com

Hawassa University College of medicine and health sciences, Hawassa, Ethiopia
}

(c) 2013 Berhan and Berhan; licensee BioMed Central Ltd. This is an Open Access article distributed under the terms of the

countries, the fertility desires were $15 \%$ in Malawi [6], $18 \%$ in Uganda [7], $41 \%$ in Ethiopia [4] and 63\% in Nigeria [8]. One of US studies also showed that the majority of HIV positive women did not have desires to be pregnant [9].

On the other hand, the fertility desire of HIV-infected individuals were reported as increasing because of increasing hope of living longer with ART, resumption of a healthy life, and the overall physical and mental wellbeing. A multivariate analysis from Uganda showed that the fertility desire of HIV-infected individuals had significantly increased with ART [10]. In Canada, the proportion of fertility desire among HIV positive women increased from about $26 \%$ in 2007 [11] to $69 \%$ in 2009 [12]. Since majorities of HIV positive women are in the 
reproductive age, a decade back the fertility desire was also predicted that many will continue to have desire for children [13]. This is because; parenthood, particularly among married couples, is an important component of their social status. As noted by two qualitative studies (South Africa and Zimbabwe), the availability of ART and prevention of perinatal HIV transmission has also positively affected childbearing desires [14,15].

Several non-comparative studies have also shown the independent association of other factors with fertility desire in HIV-infected population. A partner's desire for a child was one of the strongest predictors for women's fertility desire [16]. In another study, being younger age, having fewer living children and higher quality of life were individually associated with fertility desire [17].

In general, a systematic review including twenty nine studies has also outlined the presence of many more factors that are related to fertility desires [18]. However, by design, it was not a quantitative or pooled analysis to more powerfully estimate the true effect size. Furthermore, from previously published primary studies, it was noted that the association of fertility desire with ART, age, sex, education level, and number of children were inconsistent. Thus, the objective of this pooled analysis was to demonstrate the strength of association of these variables with fertility desire.

\section{Methods}

\section{Search strategy}

Computer based search for articles related to the fertility desire of HIV positive people was conducted in Medline, HINARI, google scholar and Cochrane library. Via HINARI, we have also searched the websites of major publishers like: Elsevier Science-Science Direct, Nature Publishing Group, Oxford University Press, PsycARTICLES, Science and Wiley-Blackwell. The search was supplemented by searching the reference lists of each retrieved article. Article search was performed by both authors $(\mathrm{YB}$ and $\mathrm{AB})$ with an alternate combination (and/or) of these search terms: "fertility desire", "fertility intention", "desire to have children", "parenthood", "motherhood", "maternity paternity", "people living with HIV", "HIV" and "ART" or "HAART".

\section{Study selection}

These meta-analyses involved studies with the following inclusion criteria: 1) studies which reported the fertility desire of HIV positive individuals in relation to one or more of the selected variables (ART experience, number of children they have, age, sex and level of education); 2) studies which were published in English; and 3) studies done from year 2000 up to June 2012. Studies were selected if they met any of these variables.

\section{Data extraction}

From the selected studies, the following information was abstracted: author, year of publication, country where the research conducted, sample size, number of HIV positive people having fertility desires (ART experience, number of children, age, sex, and level of education). Some variables were dichotomized as no child vs one and more, age less than 30 vs 30 years and above, primary or no education vs secondary and above. For these analyses, data on both fertility intention and desire were similarly entertained.

\section{Statistical analysis}

Five meta-analyses were done taking ART experience, age, sex, education level, and number of children as independent variables. The odds ratios of fertility desires were determined using the DerSimonian-Laird method (Random effects model). Heterogeneity among the studies was assessed by computing values for $\mathrm{Tau}^{2}$, Chi-square $(\mathrm{Q}), \mathrm{I}^{2}$ and P-value. When the value of $\mathrm{I}^{2}$ was greater than or equal to $50 \%$, the variation across the studies was considered as statistically significant. Sensitivity analyses were done to assess the stability of pooled values to outliers. Publication/disclosure bias was evaluated by funnel plot. All the analyses were done using Meta Analyst (Beta 3.13) software [19]. $\mathrm{P}$-value $<0.05$ was considered as statistically significant.

\section{Results}

As shown in Figure 1, for the selected search terms, it was possible to access 9003 articles. Of which, 8854 were excluded after screening the titles for their relevance to these meta-analyses. Some others were excluded because of non-comparative nature of the studies; being qualitative by design or reviews; made a comparison of fertility desires between HIV positive and negative individuals or among sero-discordant. Finally, 20 studies (one each from Brazil, Canada and France, two from US and the rest from Africa) were eligible [7,10,20-37]. The general information on the included studies is presented in Table 1.

As presented in Figure 2, out of fourteen studies included in this meta-analysis [10,20-32], twelve showed no statistically significant association of fertility desires with ART. The two studies, one showed a statistically significant increment [31] and another one reduction [32] in fertility desire with ART. As a result, the overall odds ratio demonstrated that the fertility desires of study participants were not influenced by ART (OR = 1.1; 95\% CI: $0.88-1.26)$. The testing for heterogeneity did not show much variability among the included studies $\left(\mathrm{I}^{2}=35.1 \%\right)$.

However, having no child was a strong predictor of fertility desire [20,28,31,33,34,37] (Figure 3). Although statistically significant associations were not seen in all studies, the majority of the study participants had a 


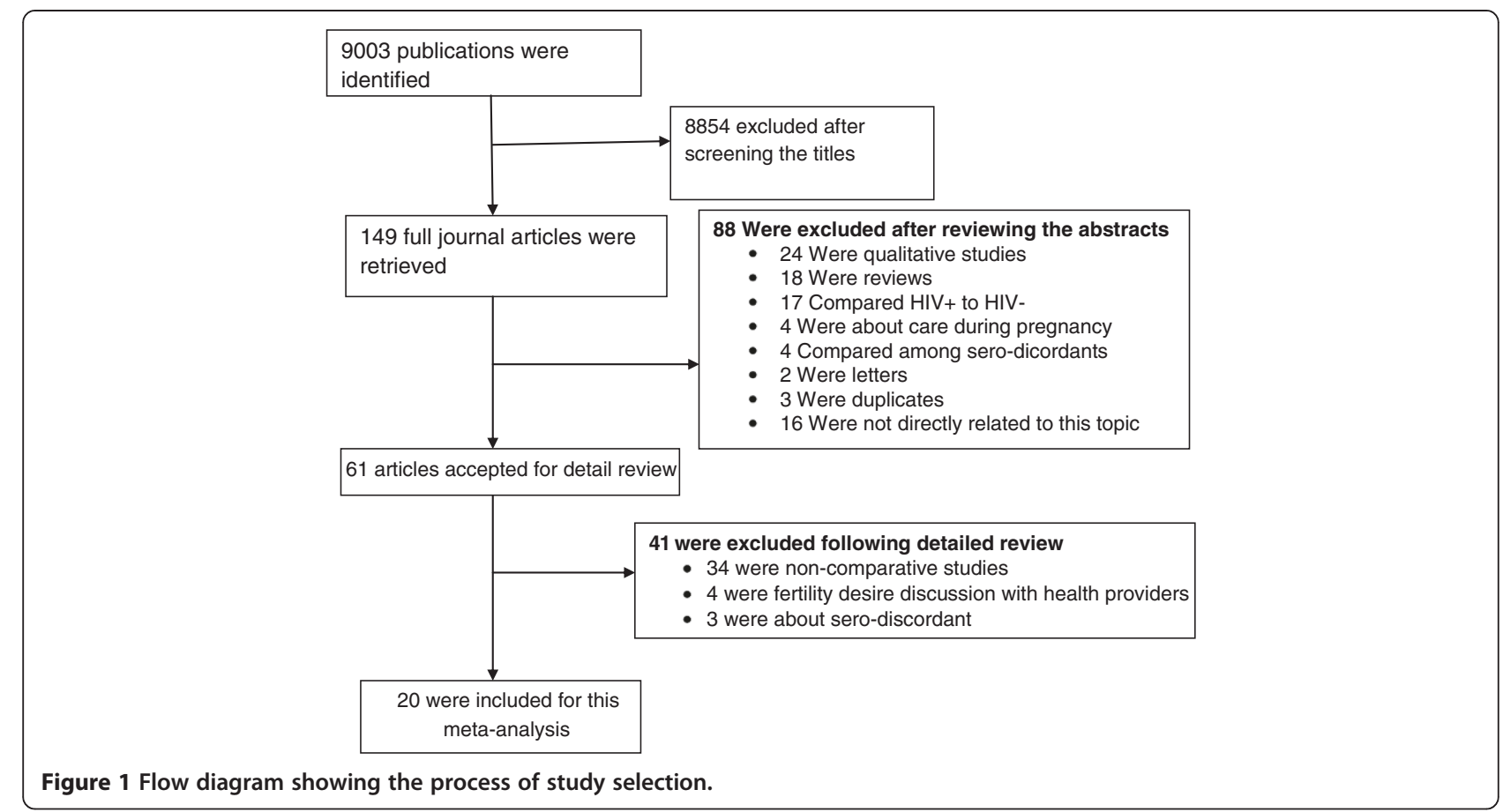

tendency for fertility desire as evidenced by the forest plot of all studies falling on the side of increased fertility desire. The pooled odds ratio also showed a significant association of fertility desire with HIV positive individuals who had no child $(\mathrm{OR}=2.9 ; 95 \% \mathrm{CI}$ : $1.77-4.95)$. The sensitivity analysis attested to the stability of the overall odds ratio. However, it should be noted that there was significant variability among the included studies $\left(\mathrm{I}^{2}=91.7 \%\right)$.

In Figure 4, another predictor for fertility desire was the age of people living with HIV. The high fertility desires

Table 1 General characteristics of studies included in these meta-analyses

\begin{tabular}{lllll}
\hline Author & Year & Country & Target & Study design \\
\hline Andia I et al. & 2009 & Uganda & Women & Cross-sectional \\
\hline Cooper D et al. & 2009 & South Africa & Men \& women & Cross-sectional \\
\hline Erhabor O et al. & 2012 & Nigeria & Women & Cross-sectional \\
\hline Finocchario-Kessler S et al. & 2010 & USA & Men \& women & Cross-sectional \\
\hline Heard I et al. & 2007 & France & Men \& women & Cross-sectional \\
\hline Iliyasu Z et al. & 2009 & Nigeria & Women & Cross-sectional \\
\hline Kaida A et al. study 2 & 2010 & South Africa & Cross-sectional \\
\hline Maier M et al. & 2009 & Uganda & Cross-sectional \\
\hline Nobrega A A et al. & 2007 & Brazil & Women & Cross-sectional \\
\hline Myer L et al. & 2007 & South Africa & Men \& women & Cross-sectional \\
\hline Nakayiwa S et al. & 2006 & Uganda & Men \& women & Cross-sectional \\
\hline Paiva V et al. & 2007 & Brazil & Women & Cross-sectional \\
\hline Stanwood N L et al. & 2007 & USA & Men \& women & Cross-sectional \\
\hline Alemayehu B et al. & 2012 & Ethiopia & Men \& women & Cross-sectional \\
\hline Getachew M et al. & 2010 & Ethiopia & Women & Cross-sectional \\
\hline Kaida A et al. study 1 & 2011 & South Africa & Women & Cross-sectional \\
\hline Kipp W et al. & 2011 & Uganda & Men \& women & Cross-sectional \\
\hline Ogilvie G S et al. & 2007 & Canada & Cross-sectional \\
\hline Tamene W et al. & 2007 & Ethiopia & Cross-sectional \\
\hline Tesfaye L et al. & 2012 & & &
\end{tabular}




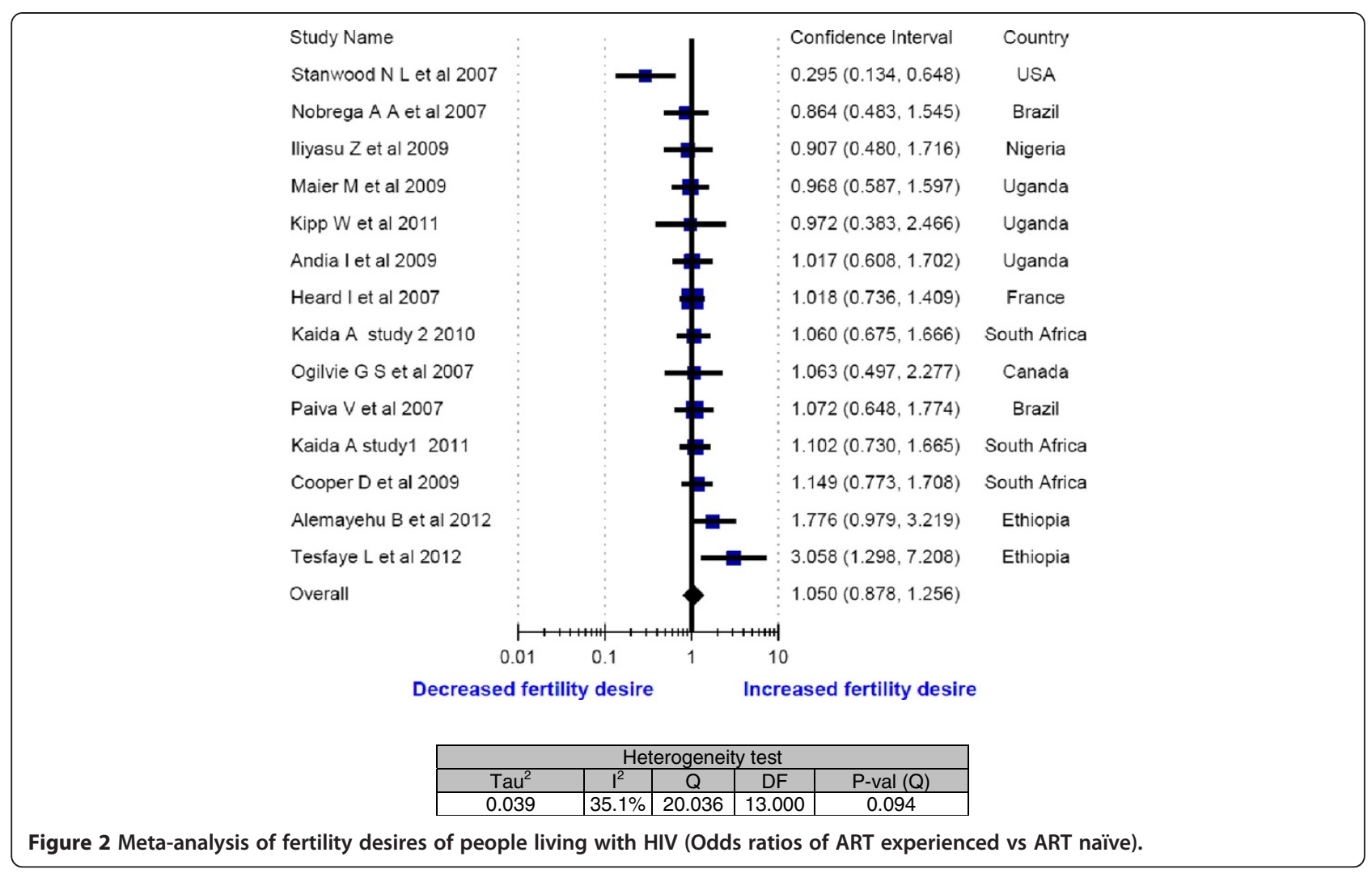

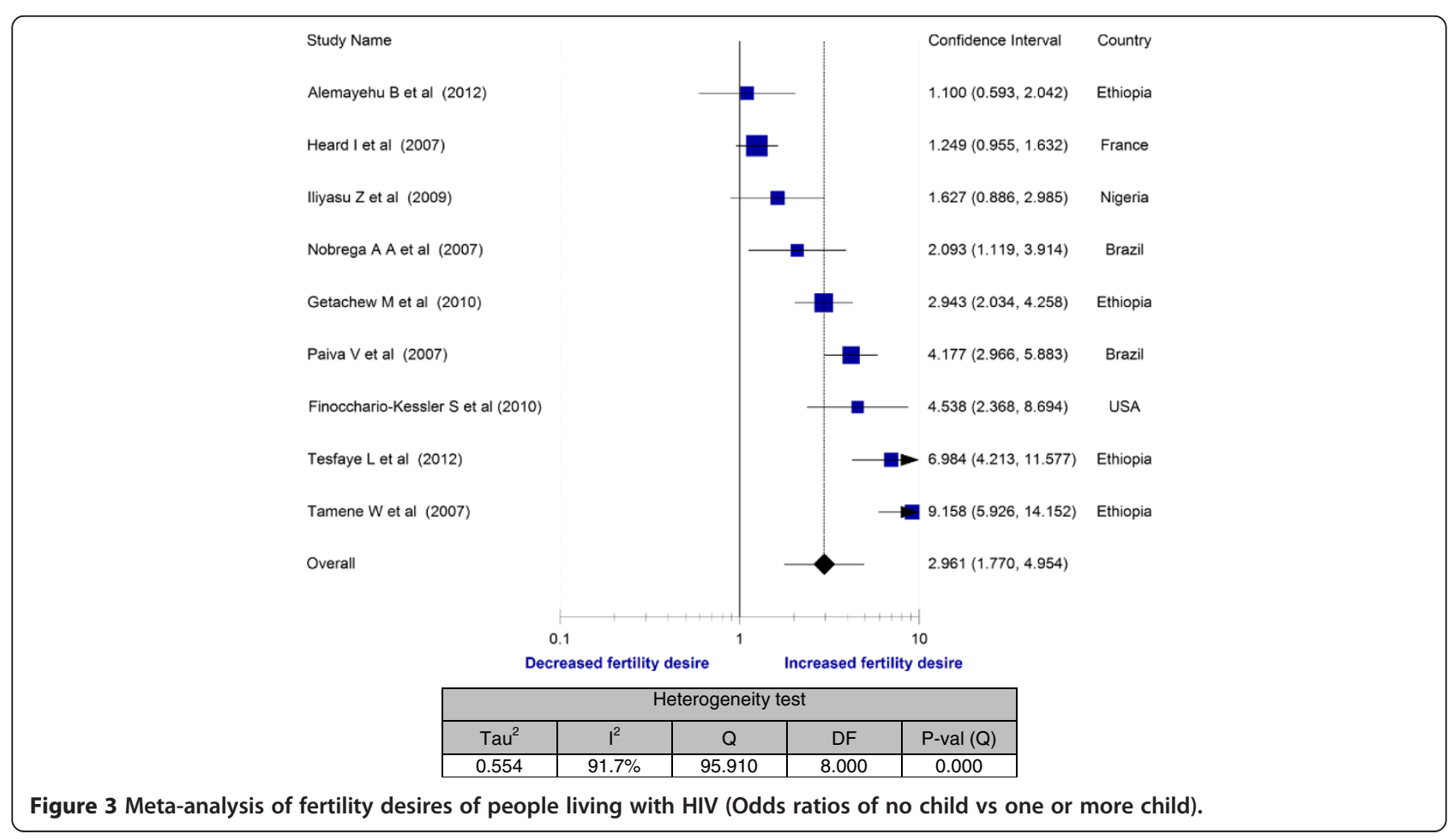




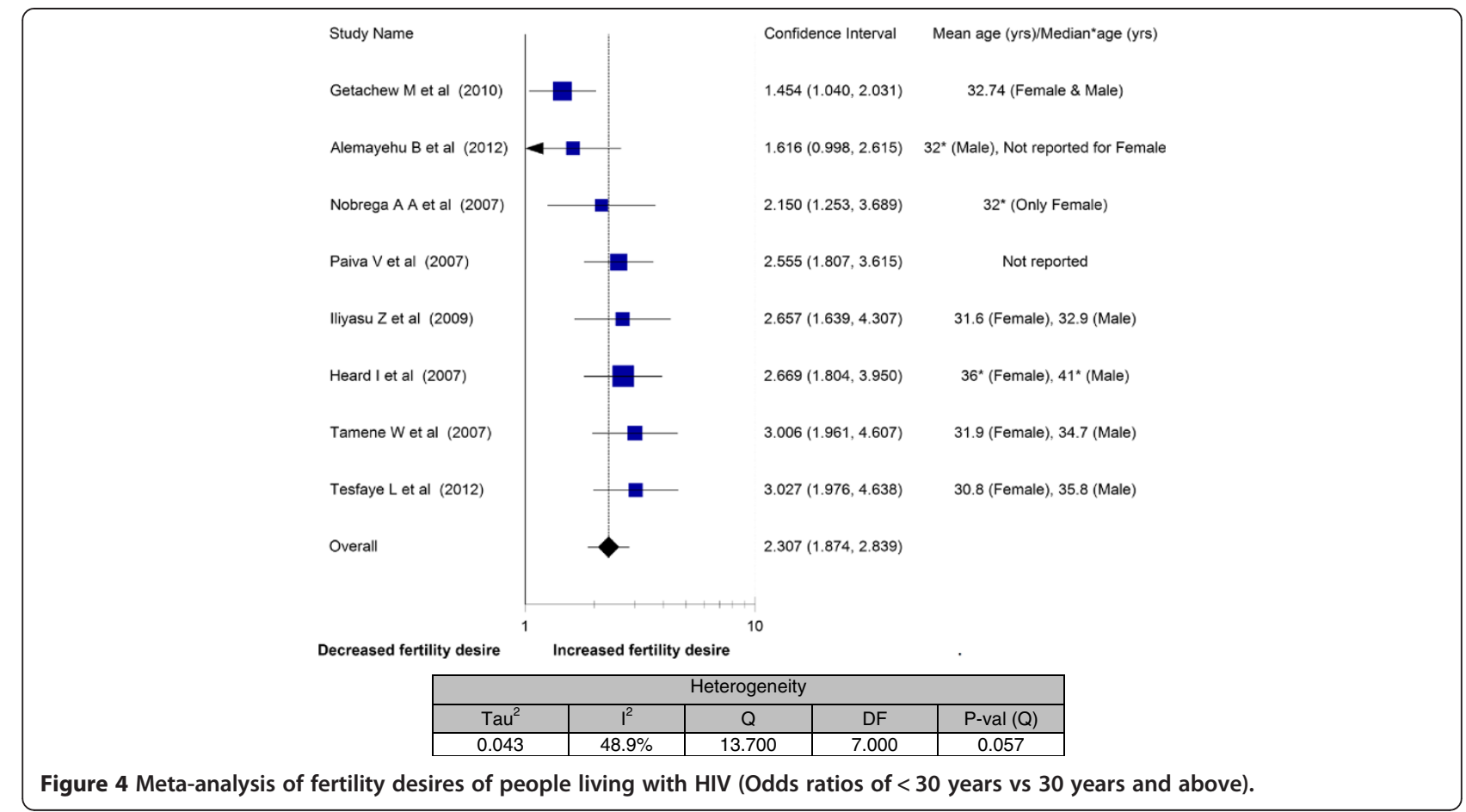

among age category below 30 years was almost a consistent finding in all included studies [20,21,26-28,31,33,34]. The fertility desires of this age category were about 1.5 to 3 -fold higher than their older counterparts. As a result, the overall odds ratio demonstrated more than 2-fold increment in fertility desire in less than 30 years of age (OR $=2.3$; $95 \%$ CI: 1.87 - 2.84). The heterogeneity testing showed moderate variability $\left(\mathrm{I}^{2}=48.9 \%\right)$.

In Figure 5, pooled analysis was done for association of sex with fertility desire by including twelve studies. In

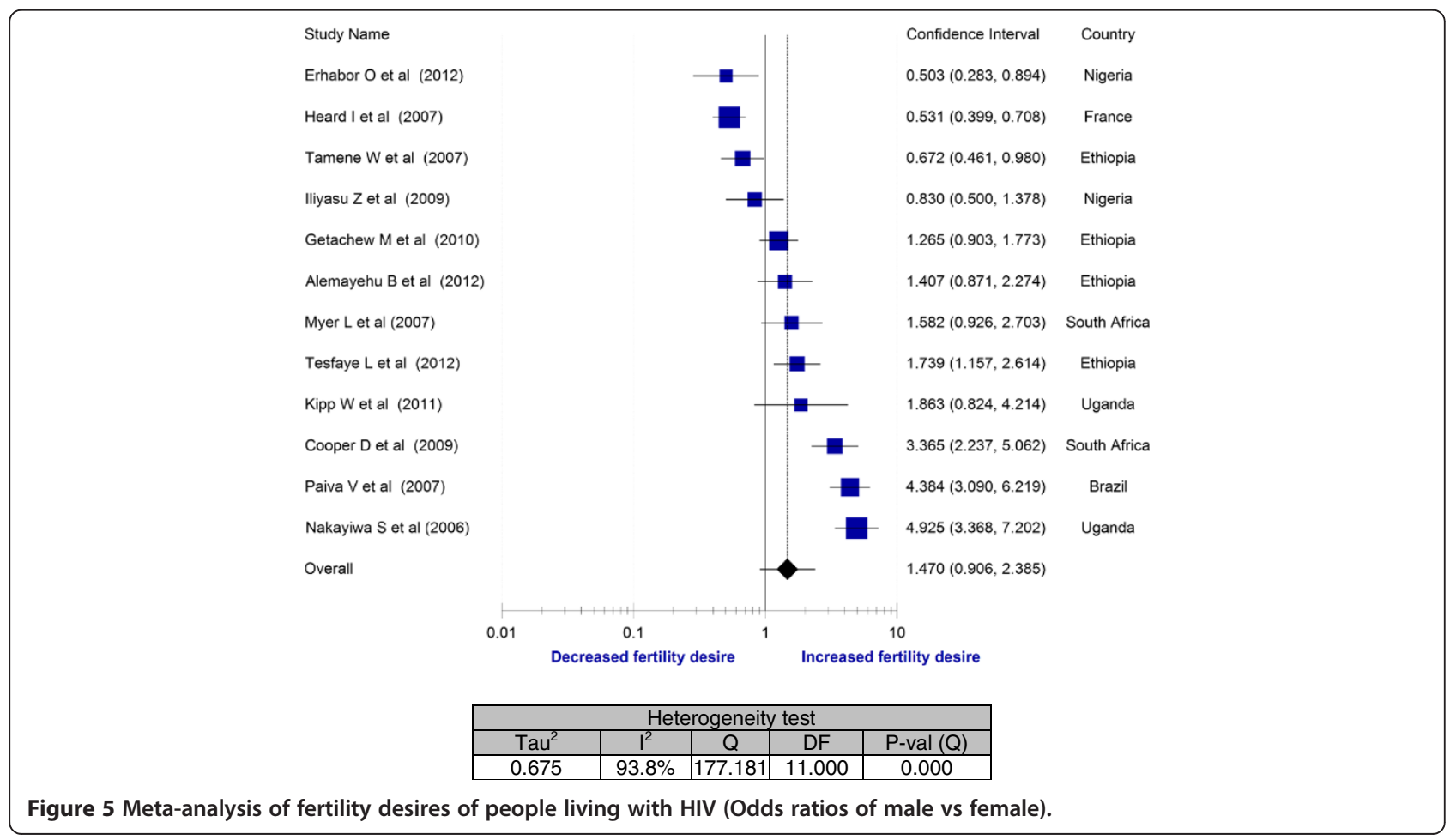


four studies, men had more fertility desires than women $[7,20,22,31]$. Other three studies showed that being woman was found to have a statistically significant association with fertility desire $[26,34,36]$. In other five studies, fertility desires were not associated with sex of respondents $[21,25,27,33,35]$. The overall odds ratio also did not show statistically significant association of fertility desire with being women or men. There was significant variability among included studies $\left(\mathrm{I}^{2}=93.8 \%\right)$.

Except one study [36], the meta-analysis of fertility desire in relation to education level did not demonstrate a strong association of fertility desire with better education (Figure 6). In four studies, the forest plot fall on the decreased fertility desire side $[20,27,28,34]$ but the pooled odds ratio was insignificant. In all these five metaanalyses, the funnel plot did not demonstrate publication or disclosure bias.

\section{Discussion}

These meta-analyses demonstrated that the fertility desire was highest among young and childless people living with HIV but was not associated with ART or educational level. ART is known to improve the overall wellbeing of HIV-infected persons [38] and many speculated that better physical health and cognitive improvements gained due to ART can improve their positive attitude towards childbearing. Similarly, a better educated people are expected to have better awareness about preventive methods of mother-to-child transmission of HIV, and as a result, their fertility desire is anticipated to be higher than the less educated individuals.

However, as these meta-analyses showed, neither their better education attainment nor being on ART was found to have an influence on their fertility desire. Rather, fertility desire was strongly associated with being young or childless, which both were likely to be interlinked one with the other and this kind of reflection is probably the reflection of the majority of human being in the fertile age regardless of HIV infection. In another study not included in this meta-analysis, being young or having few or no child was also an independent predictor for high fertility desire [16]. To the contrary, in another study, being young or single was reported to be inversely associated with fertility desire [39]. These reports showed how inconsistent the fertility desire behavior of the study participants was, which is calling for further in-depth investigation.

In general, it is a known fact that identifying the factors behind the fertility desires has paramount importance for both policy makers and health care providers. Specifically, although these meta-analyses did not demonstrate the associations of fertility desire with ART, as majority of HIV positive people are in the fertile age and living longer with ART [40,41], the authors speculate that their fertility desire is going to increase as the duration of ART advances. Unlike the previous times when high HIV prevalence in many Sub-Saharan African countries was associated with about $20 \%-40 \%$ reduction in fertility [42], we are observing that these days the

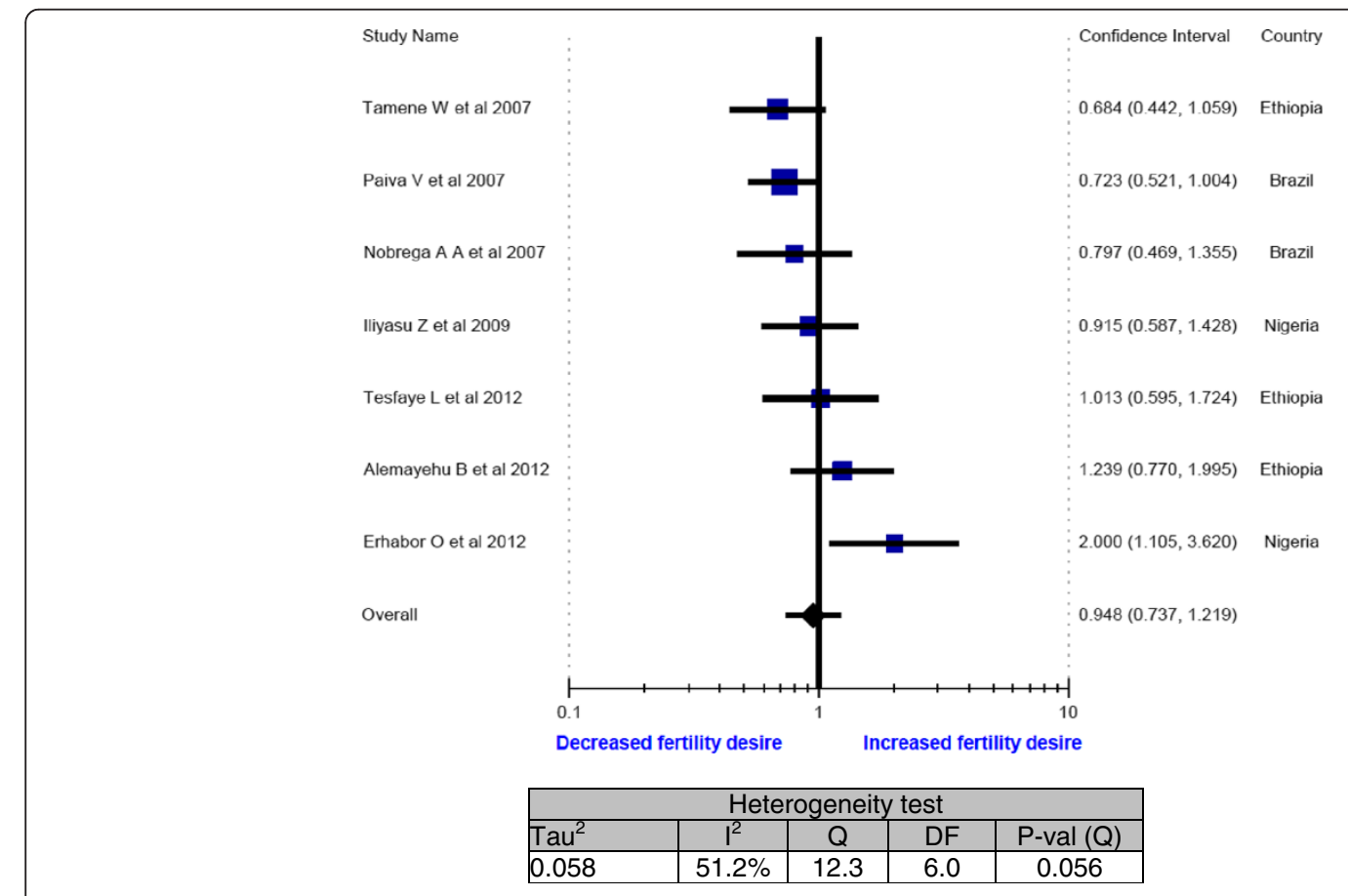

Figure 6 Meta-analysis of fertility desires of people living with HIV (Odds ratios of primary or no education vs secondary and above). 
number of pregnancies among HIV positive women is increasing, which can be taken as a proxy indicator of increasing fertility desire among people living with HIV. However, as previous studies pointed out, the fertility issue does not seem given much emphasis in the package of HIV patients follow up and care [15,22].

This is despite the fact that fertility desires of people living with HIV are serious concerns for the patients themselves, for authors in the field and health care providers $[14,15,40,43]$. This is because; from the perspective of preventing HIV transmission and socioeconomic consequences, the implication of fertility desire is multifaceted. Because of its unprotected nature of the sexual practice, there is a high chance of HIV horizontal transmission to HIV-negative and/or positive individuals (a different HIV strain, probably even resistant ones). Secondly, if the fertility desire becomes successful and pregnancy occurs, there is high concern and increased risk of HIV vertical transmission to the coming baby during pregnancy and breastfeeding $[4,40]$. Thirdly, HIV infection is known to increase the risk of orphaning.

Therefore, understanding the epidemiology of fertility desires of people living with HIV helps clinicians aware of their clients demand ahead of time and gets prepared to plan and implement the preventive modalities for both horizontal and vertical HIV transmission. This is to mean that letting the couples know the potential health risks to themselves and their babies help them make an informed decision, which is also the recommendation of other authors [15,44]. When the fertility desire comes into practice, safer pregnancies practice such as making low preconception viral load using ART and instituting the principles of prevention of mother-to-child transmission of HIV (PMTCT) during pregnancy are proven to be the best protective methods of HIV vertical transmission [44].

These meta-analyses are not without limitations. Firstly, the duration of ART was not taken into consideration. It is known that as the duration of therapy increases, the general well-being of ART patients improves $[10,38]$ and as a result may have more fertility desire, which should be an area of investigation. The reduction in vertical HIV transmission due to ART and safe delivery is also likely to increase the desire for having a biological child. The finding of about 2-fold and 3-fold increment in fertility desires in Brazil [28] and Canada [12], respectively, is another evidence to speculate the probable increment in fertility desire in the years to come.

Secondly, it is difficult to make conclusions on fertility desires taking only four variables (ART, age, sex, education and number of children) as determinants. There are other variables like culture, religion, marriage, income, partner influence, and like, which we were not able to make analyses because of either lack of or unfitness of data for meta-analyses. A systematic review by Nattabi et al. in 2009 also concluded that fertility desires are influenced by a myriad of factors (demographic, healthrelated, stigma associated, psychosocial and cultural) [18]. Thirdly, because of the sensitiveness of the fertility issue for some society, the respondents may not express their genuine desire. It was reported that most HIV positive women had not discussed their fertility desires with health care providers due to fear of anticipated negative reactions and few attempted found that the environment was unsupportive for open discussion [15,20,22,28]. Fourthly, these meta-analyses included studies mainly from Sub-Saharan Africa and few from developed countries. Thus, the findings of this analysis are unlikely to be representative of the countries where the included studies done.

\section{Conclusions}

Although the fertility desire among childless and the young group was very strong, in general, we realized that quite a significant segment of HIV-infected people has desires for fertility. The reviewed literature also identified a gap in addressing fertility issue in the routine care for HIV positive people. Therefore, including fertility issue as integral part of HIV patient care and counseling can help several of them in their reproductive decision making. Such counseling needs to focus on letting HIV positive people know the risks and methods of prevention while anticipating a pregnancy.

\section{Competing interests}

The authors declare that there is no competing interest. For this analysis, we have not got any financial or technical support.

\section{Authors' contributions}

YB wrote the whole manuscript and assisted in study selection and data analysis. AB mainly worked on the data analysis. Both authors read and approved the final manuscript.

\section{Acknowledgement}

We would like to thank World Health Organization and publishers for setting up HINARI to enable us to access the majority of the full texts retrieved.

Received: 19 July 2012 Accepted: 26 April 2013

Published: 30 April 2013

\section{References}

1. Yeatman S: HIV infection and fertility preference in rural Malawi. Stud Fam Plann 2009, 40(4):261-276.

2. Ross A, ven der Paarl L, Lubega R, Mayanja BN, Shafer LA, Whitworth J: HIV-1 disease progression and fertility: the incidence of recognized pregnancy and pregnancy outcome in Uganda. AIDS 2004, 18(5):799-804.

3. Desgrees du Lou A, Msellati P, Yao A: Impaired fertility in HIV-1 infected pregnant women; a clinic based survey in Abidjan. AIDS 1999, 13(4):517-521.

4. Berhan Y: Attitude of people living with HIV/AIDS to be a biological parent and their knowledge on MTCT reduction methods. Ethiop Med J 2008, 46(4):335-347.

5. Marcellin F, Protopopescu C, Abe C, Boyer S, Blanche J, Ongolo-Zogo P, Koulla-Shiro S, Moatti JP, Carrieri MP, Spire B: Desire for a child among 
HIV-infected women receiving antiretroviral therapy in Cameroon: results from the national survey, EVAL study. AIDS Care 2010, 22(4):441-451.

6. Hofman IF, Martinson FE, Powers KA, Chilongozi DA, Msiska ED, Kachipapa El, et al: The year-long effect of HIV-positive test results on pregnancy intentions, contraceptive use, and pregnancy incidence among Malawian women. J Acquire Immune Defic Syndr 2008, 47(4):477-483.

7. Nakayiwa S, Abang B, Packel L, Lifshay J, Purcell DW, King R, Ezati E, Mermin J, Coutinho A, Bunnel R: Desire for children and pregnancy risk behavior among HIV-infected men and women in Uganda. AIDS Behav 2006, 10:S95-S104.

8. Oladapo OT, Daniel OJ, Odusoga OL, Ayoola-Sotubo O: Fertility desires and intentions of HIV positive patients at a suburban specialist center. J Nat/ Med Assoc 2005, 97(12):1672-1681.

9. Kanniappan S, Jeyapaul MJ, Kalyanwala S: Desire for motherhood: Exploring HIV-positive women's desire, intentions and decision-making in attaining motherhood. AIDS Care 2008, 20(6):625-630.

10. Mair M, Andia I, Emenyonu N, Guzman D, Kaida A, Pepper L, Hogg R, Bangsberg DR: Antiretroviral therapy is associated with increased fertility desire, but not pregnancy or live birth, among HIV positive women in an early HIV treatment program in rural Uganda. AIDS Behav 2009, 13(1):28-37.

11. Ogilive GS, Palepu A, Remple VP, Maan E, Heath K, et al: Fertility intentions of women of reproductive age living with HIV in British Columbia, Canada. AIDS 2007, 21:S83-S88.

12. Loutfy MR, Hart TA, Mohammed SS, Su D, Ralph ED, et al: Fertility desires and intentions of HIV-positive women of reproductive age in Ontan Canada: a cross sectional study. PLoS One 2009, 4(12):e7925. www.plosone.org.

13. Siegel K, Schrimshaw EW: Reasons and justifications for considering pregnancy among women living with HIV/AIDS. Psychol Women Quart 2001, 25(2):112-123.

14. Ndlovu V: Considering childbearing in the age of highly active antiretroviral therapy (HAART): Views of HIV-positive couples. Journal of Social Aspects of HIV/AIDS 2009, 6(2):58-68.

15. Cooper D, Harris J, Myer L, Orner P, Braacken H: "Life is still going on": reproductive intentions among HIV-positive women and men in South Africa. Soc Sci Med 2007, 65(2):274-283.

16. Aska ML, Chompikul J, Keiwkarnka B: Determinants of fertility desires among HIV positive women living in the Western highlands province of Papua New Guinea. World J AIDS 2011, 1(4):198-207.

17. McClellan MK, Patel R, Kadzirange G, Chipato T, Katzenstein D: Fertility desires and condom use among HIV-positive women at an antiretroviral roll-out program in Zimbabwe. Afr J Reprod Health 2010, 14(2):27-35.

18. Barbara Nattabi B, Li J, Sandra C, Thompson SC, Orach CG, Earnest J: A systematic review of factors influencing fertility desires and intentions among people living with HIV/AIDS: implications for policy and service delivery. AIDS Behav 2009, 13(5):949-968.

19. Wallace BC, Schmid CH, Lau J, Trikalinos TA: Meta-analyst: software for meta-analysis of binary, continuous and diagnostic data. BMC Med Res Methodol 2009, 9(1). 80+. http://www.biomedcentral.com/1471-2288/9/80.

20. Paiva V, Santos N, Francia-Junior I, Filipe E, Ayres JR, Segurado A: Desire to have children: gender and reproductive rights of men and women living with HIV: a challenge to health care in Brazil. AIDS Patient Care STDS 2007, 21(4):268-277.

21. Alemayehu B, Aregay A: Desire to procreate among people living with HIV/AIDS: Determinants in Ethiopia: a cross-sectional study. J AIDS HIV Res 2012, 4(5):128-135

22. Cooper D, Moodley J, Zweigenthal V, Bekker L-G, Shah I, Myer L: Fertility intentions and reproductive health care needs of people living with HIV in Cape Town, South Africa: implications for integrating reproductive health and HIV care services. AIDS Behav 2009, 13:S38-S46.

23. Ogilvie GS, Palepu A, Remple VR, Maan E, Heath K, MacDonald G, Christilaw J, Berkowitz J, Fisher WA, Burge DR: Fertility intentions of women of reproductive age living with HIV in British Columbia, Canada. AIDS 2007, 21(Suppl 1):S83-S88.

24. Andia I, Kaida A, Maier M, Guzman D, Emenyonu N, Pepper L, Bangsberg DR, Hogg RS: Highly active antiretroviral therapy and increased use of contraceptives among HIV-positive women during expanding access to antiretroviral therapy in Mbarara, Uganda. Am J Public Health 2009, 99(2):340-347

25. Kipp W, Heys J, Jhangri G, Alibhai A, Rubaale T: Impact of antiretroviral therapy on fertility desires among HIV-infected persons in rural Uganda. Reproductive Health 2011, 8:e27. www.reproductive-health-journal.com.
26. Heard I, Sitta R, Lert F, and the VESPA study group: Reproductive choice in men and women living with HIV: evidence from a large representative sample of outpatients attending French hospitals (ANRS-EN12-VESPA study). AIDS 2007, 21(Suppl 1):S77-S82.

27. Iliyasu Z, Abubakar IS, Kabir M, Babashani M, Shuaib F, Aliyu MH: Correlates of fertility intentions among HIV/AIDS patients in Northern Nigeria. Afr J Reprod Health 2009, 13(3):71-83.

28. Nobrega AA, Oliveira FAS, Galvao MTG, Mota RS, Barbosa RM, Dourado I, Kendall C, Kerr-Pontes LRS: Desire for a child among women living with HIV/AIDS in Northeast Brazil. AIDS Patient Care STDS 2007, 21(4):261-267.

29. Kaida A, Laher F, Strathdee SA, Money D, Janssen PA, Hogg RS, Gray G: Contraceptive use and method preference among women in Soweto, South Africa. The influence of expanding access to HIV and treatment services. PLoS One 2010, 5(11):E13868. www.plosone.org.

30. Kaida A, Laher F, Strathdee SA, Money D, Janssen PA, Hogg RS, Gray G: Childbearing intentions of HIV-positive women of reproductive age in Soweto, South Africa: the influence of expanding access to HAART in an HIV hypeendemic setting. Am J Public Health 2011, 101(2):350-358.

31. Tesfaye L, Admasu M, Getachew A, Sharma HR: Fertility desires and family planning demand among HIV-positive clients in follow-up care at antiretroviral treatment unit in Gondar University hospital, Ethiopia. Vulnerable Child Youth Stud 2012, 7(1):20-35.

32. Stanwood NL, Cohn SE, Heiser JR, Pugliese MA: Contraception and fertility plans in a cohort of HIV-positive women in care. Contraception 2007, 75:294-298

33. Getachew M, Alemseged F, Abera M, Deribew A: Factors affecting fertility decisions of married men and women living with HIV in South Wollo Zone, Northeast Ethiopia. Ethiop J Health Dev 2010, 24(3):214-220.

34. Tamene W, Fantahun M: Fertility desire and family-planning demand among HIV-positive women and men undergoing antiretroviral treatment in Addis Ababa. Afr J AIDS Res 2007, 6(3):223-227.

35. Myer $L$, Morroni $C$, Rebe $K$ : Prevalence and determinants of fertility intentions of HIV-infected women and men receiving antiretroviral therapy in South Africa. AIDS Patient Care STDS 2007, 21(4):278-285.

36. Erhabor O, Akani Cl, Eyindah CE: Reproductive health options among HIV infected persons in the low-income Niger Delta of Nigeria. HIV/AIDS Res Palliat Care 2012, 4:29-35.

37. Finocchario-Kessler S, Sweat MD, Dariotis JK, Trent ME, Kerrigan DL, Keller JM Anderson JR: Understanding high fertility desires and intentions among a sample urban women living with HIV in the United states. AIDS Behav 2010, 14(5):1106-1114.

38. Homsy J, Bunnel R, Moore D, et al: Reproductive intentions and outcomes among women on antiretroviral therapy in rural Uganda: a prospective cohort study. PLoS One 2009, 4(1):e4149. www.plosone.org.

39. Kakire O, Osinde MO, Kaye DK: Factors that predict fertility desires for people living with HIV infection at a support and treatment center in Kabale, Uganda. Reprod Health 2010, 7:e27. www.reproductive-healthjournal.com

40. Gruskin S, Firestone R, MacCarthy S, Ferguson L: HIV and pregnancy intentions: do services adequately respond to women's needs? Am J Public Health 2008, 98(4):1746-1750.

41. Lima VD, Hogg RS, Harrigan PR, Moore D, Yip B, Wood E, et al: Continued improvement in survival among HIV-infected individuals with newer forms of highly active antiretroviral therapy. AIDS 2007, 21(6):685-692.

42. Zaba B, Gregson S: Measuring the impact of HIV on fertility in Africa. AIDS 1998, 12(Suppl 1):S41-S50.

43. Laher F, Todd CS, Stibich MA, Phofa R, Behane X, Mohapi L, Gray G: A qualitative assessment of decisions affecting contraceptive utilization and fertility intentions among HIV-positive women in Seweto, South Africa. AIDS Behav 2009, 13:S47-S54.

44. Joint United Nations Programme on HIV/AIDS (UNAIDS): Report on the global AIDS epidemic 2010. www.unaids.org.

doi:10.1186/1471-2458-13-409

Cite this article as: Berhan and Berhan: Meta-analyses of fertility desires of people living with HIV. BMC Public Health 2013 13:409. 